\title{
O CINEMA HAREDI DE AÇÃO - CORPOS EM MOVIMENTO
}

\section{HAREDI CINEMA IN ACTION - BODIES IN MOVEMENT}

Bruno Szlak*

\section{Resumo}

$\mathrm{O}$ artigo se baseia na tese de doutoramento do autor a ser defendida e aborda uma categoria muito especial de cinema produzido por minorias: o cinema realizado por judeus ortodoxos, especialmente em Israel. Aborda-se aqui como o cinema haredi, feito por homens, para homens e comercializado apenas através de DVDs para consumo doméstico, apropriou-se do gênero hollywoodiano dos filmes de ação. Nesse contexto, analisa-se como o corpo masculino é apresentado em comparação com a construção que o sionismo fez do corpo judaico, em seu esforço para se diferenciar do judaísmo europeu do século XIX e início do século XX. Na sequência, analisam-se aspectos estéticos e a narrativos propriamente ditos desses tipos de filmes.

Palavras-chave: Cinema Haredi, Ortodoxia Judaica, Filmes de Ação.

\begin{abstract}
The paper is based on the author's doctoral thesis and deals with a very special kind of cinema produced by minorities: movies that are made by orthodox Jews, especially in Israel. Haredi cinema, made by men, for men and marketed only through DVDs for home consumption, appropriated Hollywoodian action movies genre. In this context, I analyze how male body is presented in comparison with Zionist body construction in its efforts to differentiate itself from the European Judaism from the XIX century and the beginning of the XX century. Afterwards, I analyze aesthetic and narrative aspects of this kind of movies.
\end{abstract}

Keywords: Haredi Cinema, Jewish Orthodoxy, Action Movies.

\footnotetext{
* Doutorando do Programa de Pós-Graduação em Estudos Judaicos e Árabes da Universidade de São Paulo.
} 
A sequência de filmes de Yehuda Grovais, conhecida como $A$ vingança judaica (Hanekama HaYehudit), começa em 2000, com um filme cujo título dará nome à série, além de ter sido um dos primeiros filmes de ação no mercado haredi. Tendo sido muito bem aceito pelas audiências jovens masculinas, a fórmula foi rapidamente repetida por Grovais, que produziu uma sequência com quatro filmes: A vingança judaica 2 - a captura de Eichmann; A vingança judaica 3 - missão no Nepal; A vingança judaica 4 - o arquivo secreto; $A$ vingança judaica 5 - me tirem de minha prisão pessoal. Ao longo dos anos seguintes, muitos filmes do mesmo gênero foram produzidos por Grovais e outros cineastas.

Ainda que muito populares (os filmes podem ser vistos pelo YouTube), os filmes dessa série nunca receberam a aprovação formal das autoridades rabínicas. Ao contrário, sua popularidade despertou grande controvérsia e provocou a produção de diversos panfletos de protesto (FRIEDMAN; HAKAK, 2015, p. 55). O processo de negociação gradual para a aceitação dos filmes pelo público haredi e pelas autoridades rabínicas significa que eles são defendidos, principalmente, como ferramentas educacionais. Para que o filme possa ser acolhido pela autoridade rabínica, sua trama deve reafirmar positivamente formas consensuais de comportamento (ELIMELECH, 2009, p. 99-126). Ainda que os filmes haredim não possam ser vistos simplesmente como propaganda dos discursos haredim oficiais, suas narrativas evitam tratar diretamente de pontos sociais e ideológicos que possam ser entendidos como controversos - como o serviço militar obrigatório, por exemplo - entre as diferentes denominações ortodoxas. O status controverso de séries como A vingança judaica pode ser atribuído a certa transgressão e desafio ao discurso haredi oficial, em virtude da experimentação da linguagem fílmica (pelo menos, no universo haredi), do uso do gênero de ação proposto e, ainda, em razão do endereçamento temático da relação dos haredim com o Sionismo e com as Forças Armadas.

A apropriação do gênero de ação pelo cinema haredi está longe de ser considerada trivial. No ponto de encontro entre o mundo haredi e as convenções do cinema hollywoodiano, a apropriação do gênero engendra uma gama de significados e abre espaços para limiaridades e transgressão. A própria noção de ação desafia e subverte as ideias hegemônicas de masculinidade e do corpo, dentro do espaço do Estado Sionista. As narrativas dos filmes de ação apresentam, tipicamente, histórias redentoras de heroísmo e de asseveração da masculinidade, em que protagonistas ativos superam obstáculos numa jornada de resoluções pessoais e sociais (O’BRIEN, 2012 apud FRIEDMAN; HAKAK, 2015, p. 55). 
Embora não seja simples definir o gênero de ação, uma de suas características pertinentes é a ênfase que ele dá ao corpo e à propensão para a ação física espetacular. É disso que provém a tendência a se incluírem, nesse tipo de filme, cenas de perseguições, brigas, tiros, explosões, personagens atléticos e, cada vez mais, efeitos especiais ou animações. De acordo com Lisa Purse, o cinema de ação é precisamente definido pelo seu foco no corpo em movimento: "o corpo é um corpo fisicamente empoderado, forte, ágil e resiliente, provando a si mesmo no campo da ação e risco, e dessa maneira desempenha fantasias de empoderamento que são inerentemente declaradas e atuadas, mais do que abstraídas" (2011, p. 3).

Para Richard Slotkin (1992, p. 8), as noções de masculinidade ocidentais estão normalmente centradas na apresentação do corpo em ação e são, assim, apresentadas nos filmes de ação, associando o poder a um equilíbrio entre a força mental, o material e o corporal. As narrativas nos filmes de ação hollywoodianos, normalmente, calcam-se em histórias de heroísmo e superação ligadas à mitologia americana e à cristandade, invocando regeneração e superação por meio da violência e de sacrifício pessoal.

Essas noções de masculinidade estão em diametral oposição às noções de masculinidade e heró́smo masculino do mundo haredi. O modelo haredi idealizado de masculinidade conecta a oposição binária entre passividade/ação com o da espiritualidade/materialidade. A propósito da concepção ortodoxa de masculinidade, afirma Topel:

Os homens ortodoxos se orgulham do corpo 'delicado' e de que suas mãos revelam não ter se dedicado a trabalhos físicos. O uso de óculos também forma parte inseparável do corpo ortodoxo masculino. Finalmente, o corpo de homens e mulheres, geralmente muito pálido, indica a falta de costume de expô-lo ao sol, o que aponta a alienação da natureza e ao mesmo tempo, o respeito às regras de recato que obrigam cobrir quase que totalmente o corpo dos judeus observantes. (2011, p. 160)

Muitos grupos religiosos e fundamentalistas enfrentam dificuldades ao tentar manter, em vários assuntos, sua estrita aderência a posições religiosas, já que vivem no meio das grandes cidades ocidentais, modernas e em permanente mudança. A comunidade haredi se percebe como uma alternativa a essa cultura ocidental. Como parte de suas tentativas de se proteger das influências externas, os corpos de seus membros estão sujeitos a uma vigilância muito estreita. Seus corpos são disciplinados e controlados de acordo com o que é percebido como princípios religiosos de fé, os quais se mantêm inalterados. Qualquer pequena mudança na aparência do corpo ou em seu comportamento é considerada uma indicação de alguma pequena transgressão e uma grande ameaça para a sobrevivência da comunidade. Uma vez 
que se trata de uma comunidade que vive de acordo com os preceitos escritos nas leis, é de se esperar que os corpos dos haredim reflitam essa tendência.

O corpo masculino é construído a partir de restrições de ação, como uma rota para se atingirem níveis mais altos de espiritualidade. A ação, quando necessária, é sempre voltada para o cumprimento dos preceitos da Torá, como a colocação de filactérios e visitas a doentes. Conforme Yohai Hakak, "acredita-se que o corpo é a morada do mau instinto e a residência da impureza" (2009, p. 106). Assim, como já observado, a ação do homem religioso deve ser contida e evitar os extremos, como o relaxamento completo do físico (à semelhança de um dervixe) ou mesmo o seu fortalecimento extremo, características típicas do corpo secular. Ambas as situações são vistas como uma devoção ao corpo. Na visão ideal de masculinidade haredi, o poder está divorciado do corpo masculino e de seu desempenho em ação. O heroísmo masculino é valorizado apenas quando passivo e submisso ao poder divino. O herói é aquele que consegue controlar suas necessidades e desejos terrenos e os subordina à lógica, corporificada pelos mandamentos divinos. A noção de heroísmo não se aplica apenas às tentações da carne, mas a qualquer assunto mundano, incluindo lutar contra os inimigos. $\mathrm{O}$ verdadeiro herói é aquele que é um "herói da Torá". O herói não é aquele que vence seus inimigos, mas aquele que conquista as suas paixões.

A maneira como o corpo é encarado, trabalhado ou mostrado resulta de uma estruturação social. O corpo é constantemente moldado e modificado no curso da interação entre o discurso e as instituições nas quais os indivíduos e seus corpos interagem (FERREE; LORBER; HESS, 1999, p. XVII). Os indivíduos e seus corpos se adaptam a percepções sociais aceitas em seu grupo, mas, em paralelo, eles também as influenciam, mudando-as, e são parceiros ativos no processo de afirmação da identidade e do corpo.

Mudanças sociais normalmente provocam mudanças no corpo e nas identidades masculinas. Uma dessas mudanças sociais pode ser a transição de grupos de pessoas de um contexto social para outro ou a rápida exposição a outro modelo competitivo de corpo masculino. Deve-se notar que o corpo haredi não deve ser essencializado e que existem diferenças entre as diversas correntes ortodoxas - e mesmo entre homens de um mesmo subgrupo, mas com idades diferentes. Entretanto, dado a status hegemônico que o grupo religioso conhecido como lituano assume e devido à sua influência nas yeshivot de outros setores, a similaridade nos diferentes setores, especialmente no que se refere aos atributos escolhidos para o corpo masculino, é muito grande. O mesmo fenômeno ocorre com a 
percepção do público ortodoxo acerca do corpo laico. Certamente, não há um só corpo masculino laico e é preciso estar ciente de suas diferenças, mas, nesse caso da percepção haredi, há também uma semelhança nas manifestações e significados atribuídos.

Ainda que os encontros entre homens religiosos e laicos tenham ocorrido desde o início do movimento sionista e tenham se tornado mais frequentes após o estabelecimento do Estado de Israel, o impacto dos fatores de diferenciação era, até as últimas duas décadas, limitado. Particularmente notável foi a tendência haredi de se segregar e proteger-se dentro dos muros de suas yeshivot e kolelim, criando para si um espaço protegido, nos anos que se seguiram à criação do Estado de Israel. Uma das mudanças que esse setor experimentou, nas últimas duas décadas, foi um movimento crescente de saída de suas esferas de proteção para um amplo espectro de encontros com a sociedade israelense como um todo. Vários fatores contribuíram para esse processo - alguns ligados a forças internas da sociedade haredi, enquanto outros, a forças externas. As forças internas incluíam o crescimento demográfico e o fortalecimento político da sociedade haredi. Essas tendências aumentaram a autoconfiança dos haredim e reduziram sua necessidade de se recolher e segregar com vistas a garantir a continuidade de sua comunidade. A essas forças internas deve-se agregar o esgotamento de recursos econômicos e o processo de empobrecimento dessa população (FREIDMAN, 1991). Outro fator a se considerar é a insatisfação dos jovens com os seminários onde estudam e sua busca por assuntos mais mundanos. Já entre as forças externas está a redução significativa de apoio financeiro por parte do governo israelense para as famílias numerosas, para os estudantes e para as instituições de ensino. Acrescente-se também a diminuição do suporte financeiro advindo das comunidades religiosas estrangeiras. Essas reduções de suporte financeiro fizeram com que muitos homens e mulheres haredim se vissem forçados a buscar emprego no mercado de trabalho, e houve, portanto, uma maior penetração dos haredim na esfera pública israelense.

A questão da masculinidade e do corpo masculino na esfera religiosa vem sendo objeto de estudos e tem passado por mudanças significativas na modernidade:

Na modernidade [...] os modelos religiosos tradicionais saíram de moda, entre outras razões porque respeito, poder e autoridade foram crescentemente encontrados no interior da secularidade mais do que nos contextos eclesiásticos. Assuntos religiosos são atribuídos a esfera privada. Com o nascimento da ideia dos estados nacionais, o expansionismo colonial e o aparentemente progresso tecnológico que parece não ter fim, ideais mais "masculinos" (i.e. mais beligerantes, nacionalistas e heroicas) de masculinidade se fizeram necessários. $\mathrm{O}$ 
sentimentalismo religioso foi considerado como sendo algo privado, leve ou mesmo neurótico (como refletido no pensamento de pessoas tais como Friedrich Niestzsche até o pragmático americano Williams James). Na modernidade, repetidas tentativas foram feitas para re-masculinizar a vida na igreja. "Onde estão os homens na igreja?" é, portanto, uma questão moderna." (KRONDORFER, 2007)

Os ativistas sionistas, no final do século XIX e início do século XX, expressaram opiniões similares sobre o judaísmo tradicional, descrevendo seus homens e sues corpos como altamente femininos (BOYARIN, 1997; GLUZMAN, 1997; NORDAU, 1902). Eles diziam que, para tornar o povo judeu uma "nação como todas as outras nações", era também necessário criar um novo homem judeu, que poderia se livrar dos resquícios do exílio e adquirir uma nova e heroica masculinidade. A comunidade ultraortodoxa não seguiu por esse caminho e continuou em seus modelos religiosos tradicionais. Logo após o estabelecimento do Estado de Israel, os estudos nas yeshivot tornaram-se o único caminho normativo para todo jovem ultraortodoxo. Sob o abrigo dessas instituições, construiu-se o modelo ideal de masculino, com muitos de seus atributos identificados pela cultura ocidental como femininos. É esperado que o homem seja gentil com seu corpo; sua pele deve ser pálida, visto não estar exposta ao sol, por conta de seus intensos estudos religiosos; suas costas são, idealmente, curvadas, por ele inclinar-se constantemente sobre seus livros. Espera-se que ele evite confrontações violentas com outros homens, que limite sua sexualidade às relações maritais e se submeta à vontade de Deus. Essas yeshivot cresceram e se espalharam de maneira muito rápida, assim como o número de seus membros. Esse crescimento notável acontecia enquanto ideais de masculinidade totalmente diferentes e mesmo contraditórios eram dominantes na sociedade israelense circundante.

O corpo judaico recebeu muito pouca atenção na literatura. A religião judaica é sempre descrita como racional, e a atitude com relação ao corpo é ambivalente. Desde o seu mais remoto princípio, ela mostra considerável preocupação com a sua supervisão e restrições. $\mathrm{O}$ judaísmo proíbe o monasticismo, em contraste com as correntes principais do cristianismo e com muitas outras religiões. Com efeito, o corpo permanece como um fator essencial no caminho que leva a Deus. O objetivo complexo é a santificação do corpo, reduzindo a sua mundanidade e tornando-o espiritual, através, principalmente, de uma disciplina meticulosa, que o atrela a objetivos espirituais e à autotranscendência. $\mathrm{O}$ indivíduo está comprometido com mandamentos como "seja frutífero e se multiplique", que só pode ser realizado por meio do corpo. Mas, ao mesmo tempo, a percepção dominante é a de que o homem é criado à 
imagem e semelhança de Deus, motivando-o a se livrar de sua mundanidade e emular a espiritualidade de Deus (ELBERG-SCHWARTZ, 1992).

No exílio que se seguiu à destruição do Segundo Templo (70 DC), a atitude do judaísmo com relação ao corpo mudou. Dadas as circunstâncias da diáspora e a falta de trabalhos braçais na terra, assim como a impossibilidade de se portarem armas, algumas definições que dizem respeito ao corpo, como heroísmo e masculinidade, mudaram. Em seguida, observa-se uma intensificação da tendência de se verem como heróis e homens ideais aqueles que controlam suas necessidades e desejos terrenos e os subordinam à lógica celestial, personificada pelos mandamentos divinos. O herói não é o conquistador de fortalezas ou aniquilador de inimigos, mas "aquele que controla as suas paixões", especialmente pelo estudo de Torá. Assim, aparecem expressões como "herói da Torá", a "batalha da Torá" e o estudante que "morre sob o manto da Torá" (HAKAK, 2009, p. 106).

As restrições corporais são percebidas como condições para o florescimento da vida espiritual, um objetivo que pode ser mais bem atingido através do estudo da Torá e, principalmente, do Talmud. Essas tendências ganharam força na Idade Média - sob a influência do helenismo, que identificava o feminismo com o corpo e o mundano - e foram intensificadas, posteriormente, pelos movimentos hassídicos e o movimento conservador dos séculos XVIII e XIX. Nesse quadro, aparece a crença de que o corpo é o domicílio do mau instinto e o local da impureza (BOYARIN, 1993).

A sociedade haredi tenta preservar essas tendências e percepções na realidade da vida e dentro da sociedade israelense majoritária, onde atitudes totalmente diferentes com relação ao corpo são comuns. Essas tentativas requerem uma grande quantidade de energia. Criou-se uma nova realidade, comparada aos anos em que essas percepções eram passadas tranquilamente de pai para filho (BROWN, 2006). Sob a influência dos movimentos nacionalistas europeus, que adotaram e reviveram a cultura helenística do corpo, os líderes do movimento sionista expressaram posições semelhantes às mencionadas acima quanto à feminilidade do corpo judeu tradicional. Eles pretendiam equipar uma nova geração de homens judeus, que seriam modernos e seculares, com físicos atléticos e musculares. Esses homens seriam diferentes do judeu diaspórico, caracterizado por seu fraco corpo feminilizado. Um comportamento assertivo, manifestado de diversas formas, incluindo os níveis militar e nacional, acompanhava o novo corpo judaico. Rabinos haredim viam o estabelecimento do 
Estado de Israel como uma manifestação dessa assertividade masculina antitradicional, e alguns a julgavam como um grande pecado.

Quando do estabelecimento do Estado de Israel, a "geração da terra" 1 adotou os atributos do corpo sionista. O corpo do novo judeu deveria ser alto; musculoso, por conta de exercício físico; bronzeado, em decorrência da exposição ao sol durante o trabalho na terra. $\mathrm{O}$ homem judeu deveria ser assertivo e autoconfiante. Conforme Hakak, esse homem ideal é, ainda, um símbolo e paradigma para muitos homens judeus israelenses - particularmente, em razão da centralidade do serviço militar na sociedade israelense $(2009 \text {, p. 106 })^{2}$.

A sociedade israelense moderna está também exposta ao discurso ocidental de permissividade capitalista, que encoraja o consumo. Nesse discurso secular, as necessidades do físico e os desejos não são apenas tolerados, mas encorajados. O corpo é, então, altamente controlado e disciplinado, mas como um instrumento de grande paixão e prazer (TURNER, 1996, p. 23). Já a comunidade ortodoxa resiste a essas várias influências e continua esforçando-se para aderir aos modelos religiosos tradicionais.

Os homens religiosos e seus corpos são percebidos como "femininos" pela sociedade circundante ou pela própria descrição que fazem de si mesmos, assim como suas instituições são vistas como femininas ou feminizantes. A descrição que os jovens haredim fazem sobre os jovens laicos é muito crítica. Eles são descritos como servis e controlados por suas necessidades físicas, como libidinosos, egoístas, sem valores, materialistas, barulhentos, extrovertidos, arrogantes, vazios, superficiais e agressivos. Ademais, na sociedade maior, alguns aspectos do corpo haredi masculino formam uma alternativa desafiante aos outros corpos masculinos israelenses. Os haredim colocam, em particular, a dominação do corpo e das necessidades internas de "quem é um herói" - aquele que conquista as suas paixões - em contraste com a considerável legitimidade conseguida ao se satisfazerem as necessidades e desejos, como é comumente aceito nas sociedades ocidentais. Eles, ainda, enfatizam o seu notável comprometimento com a comunidade, em oposição ao ethos da sociedade ocidental, que coloca o individuo no centro.

Um aspecto central sobre o corpo no pensamento haredi é sua atitude perante as necessidades físicas, desejos e vontades. Enquanto, na cultura ocidental, sob a influência do discurso psicológico e do consumo, há o encorajamento da satisfação dessas necessidades e

\footnotetext{
${ }^{1}$ Aqueles que já estavam estabelecidos em Israel e trabalhavam braçalmente.

${ }^{2}$ Cf. BEN-ARI; DARASHTI, 2001; KAPLAN, 1999; LOMSKY-FEDER; RAPAPORT, 2003; SASSON-LEVI, 2006; SION, 1997; WEISS, 2002.
} 
desejos, além de sua legitimidade e, mais ainda, sua essencialidade para a saúde mental do indivíduo, a atitude haredi perante as necessidades corporais e desejos é totalmente diferente. A habilidade em controlar e restringir o corpo é descrita como um recurso fundamental para que se possa alcançar a espiritualidade requerida no convívio social. No entanto, parece que, nos últimos anos, houve algum atrito no nível de restrição e controle aplicados às necessidades físicas. Conforme Hakak, as duas principais causas que contribuem para esse fenômeno são o discurso psicológico e o consumismo, que se infiltram na sociedade haredi e legitimam as necessidades individuais (2009, p.108).

Outro aspecto central no envolvimento do haredi com seu corpo são as vestimentas, tanto privadamente como em público. Enquanto a cultura ocidental enfatiza a vestimenta e a apresentação pessoal em público como um local de autoexpressão e autorrealização, na sociedade haredi, a vestimenta manifesta o comprometimento do indivíduo com Deus e a comunidade. A vestimenta diferenciada e uniforme, ao lado de atributos como o peyot ${ }^{3}$ e a barba, é desenhada para distinguir o homem haredi dos não haredi e prevenir que eles não sejam engolidos e afetados pelos outros.

Os estudantes de Torá são lembrados que são percebidos pelos outros como representantes de Deus e sua palavra e, assim, são obrigados a ter cuidado com o seu comportamento e aparência, especialmente na esfera pública. Visto que todos os estudantes de yeshivá são compelidos a manter a respeitabilidade, as yeshivot podem ser classificadas de acordo com o seu grau de restrição, controle e autonegação requerida dos seus alunos. Isso também determinará, entre outras coisas, o grau de abertura quanto às possibilidade de algo ser mudado no jeito de se vestir.

Sob o olhar dos próprios haredim, a sua maneira de se vestir enfatiza a respeitabilidade e prestígio. A insistência em se preservar o aspecto uniforme e respeitável é bem explorada por quem vende roupas a esse setor. Mas, na última década, o que se observa é o impacto de mudanças na moda. Enquanto se supõe que a maneira de se vestir deva refletir modéstia, simplicidade e respeitabilidade, as pressões psicológicas e consumistas, já abordados aqui, e o encontro mais frequente dos haredim com outros setores da sociedade erodiram, consideravelmente, os valores de simplicidade e sua manifestação nas vestimentas. Os ternos simples usados pelos estudantes das yeshivot, até uma década atrás, deram lugar a ternos

\footnotetext{
${ }^{3} 0$ cacho de cabelo por sobre a orelha.
} 
modernos e quase que completamente idênticos aos utilizados pelos homens de negócio no mercado de trabalho moderno.

Outro fator que reforça o impacto da vestimenta corrente no Ocidente é a crescente presença do homem haredi no mercado de trabalho. Sob a capa desse processo, outro consenso foi criado: o de que muitos haredim deixam de lado o estilo de vestimenta da yeshivá - isto é, camisas brancas, o uniforme dos estudantes de Torá - e passam a usar camisas coloridas, assemelhando-se aos modernos homens de negócios. A legitimação da camisa colorida denota, de fato, um modelo físico alternativo e similar ao modelo da yeshivá. Um corpo envolto em um terno de negócios e uma camisa de botões é um corpo restringido, meticuloso e sob controle. A camisa abotoada é parte da "vestimenta de poder", a roupagem comum entre homens de negócio ou gestores, que serve de armadura contra algo que penetre no corpo e como uma barreira. Esse tipo de vestimenta torna difícil identificar o contorno do corpo e, portanto, obscurece a mirada. As linhas das camisas e dos ternos disfarçam as curvas, assim como a sua essência física e sensual, e tem a intenção de refletir controle, poder, racionalidade e masculinidade (LONGHURST, 2001). Essa mudança na vestimenta permite aos jovens haredim maior acesso ao espaço israelense laico e, ao mesmo tempo, preserva a maior parte dos atributos da uniformidade haredi de vestimenta, enfatizando sua conformidade aos valores do grupo.

Yohai Hakak tece comentários sobre a relação do corpo haredi com as atividades físicas. Outro atributo chave do corpo Haredi está conectado às práticas e envolvimentos considerados apropriados. Uma vez que o corpo é o recipiente da alma e é a ferramenta pela qual o trabalho do Criador é executado, ele deve ser mantido e alimentado tão bem quanto possível. Ao mesmo tempo, a hierarquia entre o corpo e a alma é clara, cujos objetivos finais são a santidade e funcionalidade da alma, bem como a predominância dela sobre o corpo mundano e bestial. Dado o olhar que vê o corpo apenas como um recipiente para a alma, não há razão para desenvolvê-lo em seu próprio beneficio. Assim, não há equipamentos esportivos numa yeshivá; não há aulas de educação física, e nenhum tempo é dedicado a atividades físicas. Os jornais haredim também ignoram o assunto, exceto pelas reportagens sobre tumultos em um campo de futebol, a fim de comprovarem a bestialidade secular do helenismo e da "cultura do corpo".

No entanto, atividade física limitada pode receber legitimidade parcial, caso sirva de instrumento para melhorar a habilidade de estudar. Muitos rabinos mostram algum tipo de 
apoio à atividade física dos estudantes da yeshivá e a veem como um escape para o excesso de energia e como um auxiliar para aliviar os desejos. Mas essa é uma área que, normalmente, pertence aos costumes "gentios" e, mais especificamente, à cultura grega, de forma que a atitude dos haredim é ainda hesitante e suspeitosa, tanto por parte dos rabinos como de segmentos da comunidade ortodoxa. Envolvimento nos esportes desperta muita resistência, sobretudo quando se tem a finalidade de ser mais profissional, mais sofisticado, buscar resultados e facilitar a participação em competições. O envolvimento passivo na cultura do esporte, como admirar ídolos do esporte ou assistir a jogos, também é visto com reservas. Em vez de esportes, espera-se que o jovem gaste suas energias em danças nos casamentos. Consequentemente, ir a casamentos é uma atividade muito frequente.

Ao contrario do que muitos rabinos preconizam, muitas áreas esportivas tornaram-se populares, e muitos haredim e estudantes de yeshivá passaram a praticar alguma atividade física, bem como a se interessar por eventos esportivos como espectadores. Aqui, o aumento da frequência nos encontros com o público laico desempenha um papel chave, e a isso se acrescenta o discurso médico e a preocupação crescente com a "qualidade de vida" na comunidade haredi. Evidências são fornecidas pelo aumento de ginásios e academias de ginástica nos bairros ortodoxos, aumento do número de torcedores nos jogos de futebol e daqueles que aprendem artes marciais de vários tipos. Assim como em muitas outras áreas, alguns dos principais agentes dessa mudança são haredim vindos de fora de Israel e aqueles que retornam à religião (chozer betshuva). As comunidades haredim, tanto nos Estados Unidos como na Europa, são mais abertas para a vida esportiva do que as de Israel. Esses haredim que chegam do exterior trazem consigo habilidades físicas e costumes difíceis de mudar. O discurso da saúde também confere legitimidade para o envolvimento crescente das comunidades ortodoxas com os esportes, e o uso, nos últimos anos, de termos como "centro de saúde" ou "exercícios saudáveis", no setor haredi, evidencia isso (HAKAK, 2009, p. 110111).

Mas, apesar das críticas ao corpo secular, podem-se perceber elementos indicativos de certa inveja, apreciação e deslumbre, mesmo que sua presença seja encoberta. Uma grande parte dessa inveja e deslumbramento está na percepção de que o corpo secular é mais desenvolvido, alto e forte do que o haredi. O homem não haredi é percebido como capaz de se defender, defender sua honra e sua família; ele está familiarizado com suas redondezas, não teme a natureza e tem a habilidade de influenciá-la e moldá-la às suas vontades. Em contraste, 
quando um haredi entra no espaço público maior, seu corpo é percebido como "defeituoso", e muitas de suas características são vistas como "femininas". Sua indulgência, passividade e corporalidade feminina não desenvolvida são difíceis de serem mantidas como uma alternativa. Na sociedade israelense posterior a experiência da diáspora judaica e os horrores do Holocausto, esses atributos carregam uma enorme carga negativa. Além disso, o conflito com o mundo árabe reforça a assertividade dos atributos masculinos, enquanto a economia capitalista competitiva só reforça essa tendência. Assim, o encontro entre o homem haredi e o homem secular desperta medo, especialmente no período formativo da adolescência, quando a identidade física masculina é moldada. Parece, então, que, na disputa pela hegemonia entre os modelos de masculinidade na sociedade israelense, os homens haredim são forçados a adotar atributos corporais e de masculinidade mais assertivos ${ }^{4}$.

A ação propriamente dita ou a tensão entre ação e passividade está no coração das diferenças ideológicas entre o sionismo secular e o judaísmo ultraortodoxo. A revolução efetuada na identidade do judaísmo pelo sionismo foi especialmente marcada pela ação. Ela não é vista apenas no chamado político para se tomar, com as próprias mãos, a criação do Estado Judeu - contrariamente à passividade inerente à mera observação do cumprimento da profecia da chegada do Messias -, mas na criação de um novo judeu. O novo judeu é definido, primariamente, por seu ativismo, tanto no sentido político como no sentido físico. No processo sionista de "normalizar" o diaspórico, o tradicional corpo judaico, considerado "feminino", é substituído por um novo homem, construído de acordo com o modelo masculino hegemônico da Europa ocidental. Demonstrações do físico musculoso tornam-se proeminentes e dão origem a movimentos que, no final do século XIX e início do século XX, promoviam a cultura da educação física, como o escotismo na Alemanha, por exemplo. Assim, o novo judeu, conectado com a sua terra, está pronto a defendê-la com sua força muscular e seu corpo fortalecido.

Nos últimos anos, não há como negar que há uma mudança na noção dos modelos masculinos por parte dos haredim e que existe uma maior assertividade quanto ao físico. Alguns estudos já abordam o assunto. Por exemplo, Stuart Cohen discorre sobre instituições chamadas de Yeshivot Esder para homens, onde, paralelamente ao estudo avançado de Torá, os jovens entre 18 e 23 anos prestam algum tipo de serviço militar (1993). Esse tipo de

\footnotetext{
${ }^{4}$ Para maiores informações sobre o corpo judeu e como ele é representado, bem como a construção sionista desse corpo, vejam-se as obras de Oz Almog (The Sabra) e Raz Yosef (Bodies of Redemption: Zionism, Masculinity and Cinema) entre outras.
} 
yeshivá está ligado ao movimento religioso nacionalista e foi uma maneira que o exército e os setores religiosos nacionalistas encontraram para permitir o estudo dos meninos em yeshivot e, ao mesmo tempo, o serviço ao exército, obrigatório para jovens que estão na mesma faixa etária.

O crescimento demográfico e de poder político da sociedade Haredi nos últimos 30 anos foi acompanhado por um crescente sentimento de confiança por parte dessa comunidade, abalada, desde meados do século XX, tanto pelo Holocausto europeu como pela supremacia do sionismo laico. Somada a esse sentimento de confiança, a exposição de muitos homens haredim da redoma fechada e protegida do espaço ortodoxo à sociedade israelense maior os colocou em competição com novos modelos masculinos, apesar da desaprovação das autoridades rabínicas, que tentam preservar uma percepção de vida que enxerga o Estado de Israel laico como um "exílio espiritual". No discurso oficial dos rabinos, a única forma de ação que poderia terminar com esse estado de "exílio espiritual" seria a ação religiosa, ou seja, mais estudos da Torá e maior comprometimento com o cumprimento dos preceitos religiosos (mitzvot).

Assim, crescentes incidentes de protestos políticos entre os haredim, incluindo sinais de violência física e verbal - evidência de que alguns jovens haredim queiram se juntar ao exército e se engajar na guinada política da sociedade israelense em direção à direita -, têm uma dimensão relacionada ao próprio corpo. De fato, "ao adotar tal estilo e ideologia mais rudes, os haredim manifestam seu desejo de possuir um corpo. Parece ser essa uma expressão subliminar de sua fascinação com as coisas que foram longamente pensadas serem território dos sionistas, e da qual os ultraortodoxos foram privados: fisicalidade, masculinidade e busca por ação" (ARAN; BEM-ARI; STADLER, 2008, p. 25).

Adotando certas características do gênero, os filmes de ação haredim incluem cenas de intensa ação física, como perseguições, brigas e tiroteios. Isso é geralmente sublinhado pelo gênero do Western, com música em ritmo acelerado, relacionando o filme com o gênero popular. A retratação da violência e do corpo masculino emula as convenções hollywoodianas da era clássica, distanciando-se imensamente da violência hiper-realista e sangrenta, do uso intenso de efeitos especiais e da montagem truncada que caracterizam as produções atuais do gênero. Embora tais procedimentos possam parecer arcaicos e, por vezes, mostrar certa falta de suspense, esse não é o caso para o público-alvo, pouco exposto às produções hollywoodianas. 
No caso da série Jewish revenge, a experiência visual do cinema de ação alude não apenas ao desejo dos espectadores haredim de possuir um corpo, mas a um desejo de corporificar uma posição mais ativa na mitologia nacional israelense. Ao fornecer um produto "nacional" e "kasher", que, de certa maneira, atendem aos anseios do público jovem haredi, Grovais posiciona suas tramas dentro de temas contemporâneos e históricos da esfera do sionismo militante, evocando, com plena seriedade, tropos da mitologia sionista que, havia muito, tinham sido abandonados pelo cinema israelense contemporâneo.

Os cinco filmes da série compartilham argumentos e estruturas narrativas clássicas similares. Trata-se de narrativas que remetem a missões nacionais, como, por exemplo, a captura de Adolf Eichmann, na Argentina, pelo Mossad - evento que poderia ser enxergado como uma das maneiras pelas quais o jovem Estado Sionista afirmava sua capacidade de buscar seus inimigos onde quer que estivessem, transformando-se no braço vingador de todo o povo judeu.

No centro das narrativas, homens seculares israelenses encontram-se com homens haredim em ambientes de homens não judeus e hostis. Com raríssimas exceções, esses homens não judeus são apresentados como personagens unidimensionais e retratados estereotipicamente como não confiáveis - por vezes, maus e, em outras ocasiões, inadequados ou estúpidos. Sua única função na trama é fornecer o background para um relacionamento muito mais significativo que se revela: o do agente do Mossad com a personagem haredi.

O encontro significativo vai além dos retratos estereotipados do israelense no discurso haredi. Visto que, em muitos enclaves religiosos, a sociedade haredi está sob constante ameaça de defecção de seus membros, o discurso prevalente posiciona o israelense secular como o mal que está fora, contra quem a identidade interna e esclarecida do haredi é construída. A imagem estereotipada do israelense secular como símbolo do mal é mantida pela noção de que qualquer contato com o corpo israelense deve ser limitado ou evitado totalmente.

No texto de Friedman e Hakak (2015, p. 13), é citada a análise de Vered Elimelech sobre o cinema haredi:

[...] Vered Elimelech demonstrou que o encontro com o outro - o não judeu ou o judeu secular - é central em muitos filmes haredim. Meramente por expor a imagem do outro ao público haredi, o cinema Haredi já se desvia do discurso dominante. Fazendo uma distinção entre a "primeira geração" de produções haredim (2000-2003) e a segunda geração de filmes (2003-2010), Elimelech aponta uma mudança na construção do Outro. 
Nos primeiros filmes, o Outro - seja secular israelense ou não-judeu - é mostrado como uma personagem unidimensional, usualmente desprovido de faculdades espirituais e intelectuais, cujas funções principais na narrativa é a de atuar como uma antítese ao herói haredi. Em alguns dos últimos filmes, as personagens não-haredim são mais nuançados. Enquanto que, em última instância, sua função seja a de reforçar o conjunto de valores haredim, a narrativa expõe suas considerações e motivações e ao fazê-lo, os privilegia e transgride o discurso hegemônico. $(2015$, p. 13)

Na série Jewish revenge, o israelense secular é um agente da história. A trama se desenrola ao seu redor, e o ponto de vista dos espectadores é normalmente alinhado com o dele, de forma que o conflito dramático no coração da trama é motivado por sua história. É apenas no ponto da crise, quando ele está diante de obstáculos crescentes, prestes a completar a sua missão, que o herói israelense encontra o herói haredi. Duas coisas importantes acontecem durante o encontro entre as duas personagens principais dos filmes: a primeira é que o herói haredi deixa o espaço protegido de sua comunidade e seu trabalho espiritual e se envolve, física e mentalmente, em assuntos do Estado secular. Inicialmente relutante, ele prova-se central para o sucesso da missão, na qual o corpo haredi é também engajado. O herói haredi é visto também participando em perseguições, ocultando e descobrindo documentos e até confrontando fisicamente os não judeus. Em segundo lugar, ao se envolver com a missão nacional, o herói haredi facilita a transformação da visão global do judeu secular, explicandolhe a verdadeira natureza da vingança judaica. Mais do que combates físicos e retaliações, a verdadeira vingança judaica é guiada pelo trabalho espiritual de Deus e a continuidade da vida tradicional judaica. Essa transformação, sendo revelada ao judeu secular, desfaz o conflito no coração da trama e leva à resolução. A missão é completada, apesar de todas as expectativas contrárias, e um novo estado de equilíbrio é alcançado, no qual o herói secular está mais próximo de sua identidade judaica.

Isso é bem exemplificado no primeiro filme da série, em que um agente do Mossad é enviado em missão à Ucrânia. A natureza da missão liga claramente o Holocausto ao conflito árabe-israelense: um fugitivo nazista é encontrado vivendo sob falsa identidade na Ucrânia e está envolvido no contrabando de armas para o Hezbollah. O agente do Mossad é enviado para sequestrá-lo e levá-lo para julgamento em Israel. Esse agente do Mossad tem interesse pessoal no caso. O criminoso nazista havia sido o torturador de seu pai no campo de concentração, e, assim, o agente vê a possibilidade de uma vingança pessoal também. No caminho para visitar seu pai, antes de viajar para a Ucrânia, ele passa por um emissário 
Chabad $^{5}$, que o insta a colocar um tefilim ${ }^{6}$. A princípio reticente, ele finalmente aceita a sugestão. Na conversa casual que se segue, o emissário conta que tem um irmão e que ele está na Ucrânia também como emissário Chabad. "Que coincidência!”, fala o agente, "estou a caminho de lá". O emissário Chabad fornece o endereço para o agente que, displicentemente, o anota. A cena tem duas funções: a primeira, caracterização, estabelece a atitude do agente diante da religião; a segunda, prenunciação, funciona como um aparato narrativo, fornecendo desenvolvimentos posteriores à trama. Já nesse ponto, Jewish revenge revela a proposição subversiva da série: o agente do Mossad, arquétipo sionista, é apresentado positivamente embora dissimulado e desprovido, talvez, de autoconsciência, além de muito preocupado com os assuntos mundanos -, muito longe de ser demonizado como símbolo do mal. Além disso, os tefilim têm um significado simbólico na cena. O mandamento de usar tefilim tem como finalidade permitir à pessoa alcançar a unidade entre cérebro e coração. Na filosofia hassídica, o intelecto deve controlar as emoções. Mas o agente do Mossad, como visto em cenas anteriores, é controlado pelas emoções, o que enevoa seus julgamentos intelectuais. Obviamente, ele não está consciente do significado desse encontro e é apenas em retrospectiva que o ato assume sentido como o início de sua jornada intelectual e espiritual, que produz a sua transformação. Depois dessa cena, o agente viaja para a Ucrânia. A missão não corre bem, seu disfarce é descoberto, ele desconfia que o seu contato na Ucrânia o tenha traído e, então, se vê fugindo da polícia (aliás, a polícia é apresentada como ridícula, tanto em seus uniformes como em suas ações). Nesse momento de crise, que constitui o evento motivador da trama, ele se recorda das palavras do emissário Chabad em Jerusalém e começa a procurar pelo endereço do irmão. Ele o encontra, e somos, então, apresentados ao emissário de Chabad na Ucrânia, que se tornará o herói haredi do filme.

Na casa do emissário, o agente do Mossad é acolhido para a noite. Já nesses primeiros momentos, como na manhã seguinte, a fantasia cinematográfica permite instantes de transgressão, quando como, por exemplo, o agente do Mossad, necessitado de novas roupas, coloca roupas usualmente utilizadas pelos seguidores de Chabad ${ }^{7}$. Um momento mais claro de transgressão acontece na cena subsequente, quando os dois discutem a missão, e o agente

\footnotetext{
${ }^{5}$ Um dos grupos mais expressivos em sua atuação na ortodoxia judaica é o grupo Chabad Lubavitch, orginário da cidade de Lubavitch, na Europa Oriental, no século XVIII. Sua sede atual está em Nova York, e uma de suas maneiras de espalhar sua ação é através do envio de emissários (shluchim) para os quatro cantos do mundo.

${ }^{6}$ Tefilim são os filactérios judaicos, que, de acordo com a lei judaica, todo homem deve colocar diariamente, durante a reza da manhã.

${ }^{7}$ Terno preto, camisa branca e chapéu tipo Borsalino.
} 
do Mossad pede que o emissário se envolva diretamente nela. Este, porém, recusa a solicitação, visivelmente desconfortável com o pedido, mas, quando o agente revela a natureza altamente secreta de sua missão, o emissário de Chabad declara: "Nós temos que impedi-los". Assim, o emissário de Chabad transgride as fronteiras de sua comunidade em benefício da nação e, ao fazer isso, é impelido à ação física. A cena é cortada para um ato de ação, em que se retrata o emissário, e não o agente do Mossad, como o "corpo em ação". A câmera, sujeita a convenções genéricas, segue o emissário correndo, e a ação é pontuada por uma música de ação genérica, tornando a cena um momento de espetáculo. Visto da perspectiva haredi, essa não é uma imagem trivial. Correr é um assunto de grande importância, pois constitui uma situação física extrema, a qual o corpo haredi deve evitar. É raro e, em muitos casos, obsceno que um haredi corra (ARAN, 2003, p. 118-119).

O segundo ato da trama mistura a busca para completar a missão nacional com o desenvolvimento da relação entre o agente do Mossad e o emissário de Chabad e das transformações por que ambos estão passando. O envolvimento do emissário com a missão nacional torna-se transformativa quando chega a notícia da morte do pai do agente do Mossad. Para o agente, a missão perdeu seu sentido; ele está sobrecarregado por suas emoções, mas o emissário de Chabad, gentilmente, o conduz nos assuntos da lei judaica, explicando o sentido das leis e práticas do luto e ensinando-o a lidar com o Holocausto e a natureza da vingança judaica. É aqui que a mensagem educativa do filme é explicitamente articulada pelo emissário de Chabad, que diz: "Você sabe, Yoav, eu acho que a vingança real é o fato de que você esteja ainda aqui. O que os nazistas, yimach shmam ${ }^{8}$, tentaram fazer foi destruir o nosso povo. Nossa vingança é a continuação do povo judeu, que nós continuamos vivendo e fazendo. Você entende, a vingança real é continuar a tradição judaica".

A diferença entre o impulso emocional de Yoav (o agente do Mossad) para se vingar por meio da violência e a resposta mais elaborada de Shneor (o emissário Chabad) reflete a oposição entre os discursos sionista e haredi. A cena também revela os sentidos opostos ao Holocausto por esses discursos. Conforme Hakak (2005), enquanto, no sionismo e em outras respostas seculares ao Holocausto, algum ato de retaliação é necessário, na visão de mundo haredi, o Holocausto, bem como qualquer outro desastre mundano, ocorreu por vontade divina, e é apenas Deus que pode retaliar ou punir os seus perpetradores (HAKAK, 2005, p. $82-84)$.

\footnotetext{
8 "Malditos sejam", em hebraico (tradução livre).
} 
Ainda, em uma cena posterior, quando Yoav, em seu desespero, planeja matar o criminoso nazista, Shneor o convence a deixar sua arma e concebe um plano não violento para capturar o nazista. Isso leva ao sucesso da missão. O criminoso é exposto e capturado pelas autoridades ucranianas e transferido para Israel.

Grovais se apropria das convenções do gênero de maneiras significativas. Se, nos filmes de Hollywood, o clímax é atingido em cenas de ação, Grovais constrói o clímax de sua narrativa a partir de colapsos mentais e dilemas intelectuais/espirituais. Nos pontos de alta tensão, crucialmente, o conflito central é encaminhado para uma resolução que não envolve a demonstração de força física ou atitude mental, mas o questionamento intelectual e a aceitação espiritual da vontade divina. É significativo que o filme não termine quando a missão nacional é concluída, uma vez que o ponto focal do filme é a relação entre Yoav e Shneor, e não a missão em si. A penúltima cena é uma conversa de "peito aberto" entre os dois. O diálogo articula objetivos comuns e pontos de similaridade:

YOAV: Eu realmente fico te devendo por isso.

SHNEOR: Imagina... Eu fiz apenas a minha obrigação.

(Entra uma música lírica)

YOAV: Eu já tive missões mais difíceis anteriormente, mas nunca vou me esquecer dessa. A morte de meu pai, as conversas que tivemos me deram uma perspectiva inteiramente nova.

SHNEOR: Eu usualmente me pergunto o que estou fazendo aqui... mas, então, eu conheço um judeu querido como você, e tudo entra em seus devidos lugares... Eu, às vezes, me sinto como um agente adormecido. De repente, ele é chamado para executar uma missão e, imediatamente, ele acorda, executa a missão exatamente de acordo com o planejado.

Então, os dois se despedem no aeroporto com um abraço fraternal. A diferença visível entre eles é quase apagada pelas suas roupas quase idênticas e pelo contato físico que transcende as convenções haredim de evitamento e afastamento. A cena final do filme se passa no túmulo do pai de Yoav. Observando as práticas da lei judaica, ele confessa, agora, entender o verdadeiro sentido da vingança judaica.

A fantasia do salvamento - salvar as almas perdidas dos judeus seculares e, através disso, redimir o Estado de Israel, fazendo-o ser um verdadeiro Estado judaico - serve bem ao discurso interno da comunidade haredi, especialmente aos hassidim de Gur, grupo a que Grovais é filiado, assim como ao movimento Chabad. Vislumbres dessa mesma fantasia podem ser encontrados em outros filmes para haredim (Mivtza Keshet e Avudim ba Derech, 2005), em que as narrativas apresentam israelenses seculares que retornam à religião através 
de seus encontros com personagens haredim. A série Jewish revenge diferencia-se por oferecer não apenas o preenchimento da missão Chabad (de retorno do secular à religião), mas, como Grovais coloca, "uma fantasia de masculinidade nacional”. Ela remete, diz ele, "à fantasia secreta de muitos jovens haredim de tomar parte em defender o Estado de Israel". 9

O cinema haredi pode ser pensado como uma forma de cinema digital de minoria. Nas últimas décadas, observa-se a emergência de cinemas de minoria em diferentes locais e em meio a realidades sociais diversas, seja de populações nativas, seja de comunidades de imigrantes. Esses tipos de cinema, conforme Faye Ginsburg, são "veículos para comunicação interna e externa, para autodeterminação e para resistência da supremacia da cultura dominante" (2002, p. 210). Usualmente, a análise desse tipo de filmes enfatiza sua função como "contracinema", buscando, ao se apropriar das formas da mídia e do cinema ocidental e ao desenvolver práticas estéticas alternativas, desfazer os legados da má apresentação de certos grupos nas culturas dominantes.

O cinema haredi compartilha algumas dessas características. Ele se apropria das formas do cinema ocidental e serve como veículo de comunicação interna que desafia, de maneiras importantes, o discurso dominante haredi ${ }^{10}$, ainda que os produtores haredim coloquem pouca ênfase na comunicação externa com o público maior israelense. Ao fazer isso, o olhar voltado para dentro do cinema haredi - produzindo "filmes para haredim, e não sobre haredim," conforme palavras de Grovais - reflete a tendência proeminente dos haredim em Israel de se integrarem, mas não de serem assimilados.

O gênero de filmes de ação, cuja característica primaria é criar espetáculos de ação física e uso do corpo, foi apropriado e ajustado pelo cinema haredi de diversas maneiras, o qual aderiu ao princípio básico de separação de gêneros, mudando de uma ênfase genérica no combate físico para desafios mais cerebrais. Dessa maneira, a emulação do gênero permitiu, por um lado, a fantasia da masculinidade física e, por outro, a asserção dos valores haredim.

A emergência do cinema haredi israelense como um todo e, em particular, a série Jewish revenge pode ser vista no contexto das transformações do engajamento dos haredim com a sociedade israelense maior e com o sionismo, ao longo das últimas décadas. Nos anos recentes, vê-se um movimento crescente da então protegida e separada comunidade ortodoxa em direção a uma variedade mais ampla de conjuntos da esfera pública israelense, incluindo o

\footnotetext{
${ }^{9}$ Entrevista de Grovais para Yael Friedman, em 8 de outubro de 2013.

${ }^{10}$ Outro trabalho de pesquisa mais detalhado poderia abordar o tema das reações do mundo haredi, vistas através de publicações, sobre filmes produzidos por haredim tanto para homens como para mulheres.
} 
exército, de maneira que e os pontos de contato e encontros sociais entre haredim e seculares estão aumentando.

Apesar de emular os gêneros escapistas de Hollywood, as narrativas de muitos dos filmes estão colocadas dentro do contexto sócio-político israelense e tratam do relacionamento entre os haredim e a sociedade maior. Os filmes atuam com locais visuais, em que o haredi encontra o Outro, o sionista israelense secular. O engajamento particular dos filmes da série Jewish revenge com segurança, militarismo e as forças armadas de Israel reflete a longa controvérsia sobre o serviço dos haredim servirem às forças armadas - situação que é não apenas a causa de divisões profundas entre o público haredi, mas também uma área chave na tensão entre os haredim e a sociedade como um todo. Friedman e Hakak (2015) asseveram que a sociedade israelense vê o serviço militar como um "rito de passagem" para dentro do corpo nacional israelense e enxerga a recusa oficial dos haredim de cumprirem o serviço militar como uma fuga da obrigação moral que eles devem a seu país.

Os filmes da série Jewish revenge abordam o já existente desejo dos haredim de servirem ao exército, apesar da posição oficial das autoridades rabínicas. De acordo com Grovais, as tramas ficcionais dos filmes conversam com um crescente número de jovens haredim que sonham em tomar parte na tarefa nacional de "defender Israel". "O problema para os haredim", ele sugere, "não é o serviço militar em si, mas o de assimilar o que o acompanha. No momento em que o assunto se transformou em uma luta política entre os haredim e a sociedade israelense, o público haredi sente a necessidade de resistir e defender sua autonomia".

Nos filmes, os encontros imaginados entre as personagens haredim e as forças armadas israelenses fornecem oportunidades para resolver essas diferenças. O relacionamento entre os haredim e os sionistas seculares israelenses é retrabalhado através de um conjunto de negociações, as quais levam à transgressão dos posicionamentos de ambas as partes. Se, tradicionalmente, as atitudes dos grupos haredim variam de antissionismo até a cooperação estratégica com o sionismo, a fantasia de uma relação diferente nos filmes move-se além da estratégia, indo para o domínio dos valores compartilhados.

Dirigidos a um discurso interno dos haredim, os filmes parecem oferecer aos espectadores uma construção mais empática do judeu israelense e a oportunidade de “pertencer” e influenciar a ação sionista. É o espaço "seguro" que a narrativa cinematográfica oferece para a projeção de desejos e ansiedades, onde jovens haredim podem exercer suas 
fantasias de masculinidade nacional, projetando-as não apenas na tela, mas nos espaços privados de suas casas, longe da supervisão pública (que é tão impregnada no estilo de vida haredi). Além disso, ao posicionar as tramas na contemporaneidade e em contextos históricos, os filmes reescrevem o imaginário nacional israelense e colocam um lugar para o judeu haredi - anteriormente excluído e isolado - no corpo nacional israelense. 


\section{Bibliografia}

ARAN, G. The Haredi body: chapters from Ethnography in preparation. In: CAPLAN, K.; SIVAN, E. Israeli Haredim: integration without assimilation? Jerusalem: Van Leer Institute/Hakibbutz Hameuchad Publishing House, 2003.

ARAN, G.; BEN-ARI, E.; STADLER, N. Fundamentalism and the masculine body: the case of Jewish ultra-orthodox men in Israel. Religion, 38, 2008.

BOYARIN, D. Carnal Israel: reading sex in Talmudic culture. Berkeley: University Of California Press, 1993.

BROWN, B. The range of orthodox responses: Ashkenazim and Sepharadim. In: RAVITZKY, A. (Ed.). Shas: cultural and ideological perspectives. Tel Aviv: Am Oved, 2006 p.41-122.

COHEN, S. The Hesder Yeshivot in Israel: a church-state military arrangement. Journal of Church and State, 35, p. 113-130, 1993.

ELBERG-SCHWARTZ, H. People of the body: Jews and Judaism from an embodied perspective. Albany: State University of New York Press, 1992.

ELIMELECH, V. From the far past to the present: Rabbis in Haredi cinema. In: CAPLAN, K.; STADLER, N. (Ed.). Leadership and authority in the Haredi society in Israel. Tel Aviv: Van Leer Jerusalem Institute/Hakibutz Hameuchad Publishing House, 2009.

FERREE, M.; LORBER, M.; HESS, B. Revisioning gender. Thousand Oaks: Sage Publications, 1999.

FREIDMAN, M. Haredi society: origins, trends, and processes. Jerusalem: Jerusalem Institute of Israel Studies, 1991.

FRIEDMAN, Y.; HAKAK, Y. Haredi action in the Zionist sphere. Jewish Film \& New Media, vol. 3, n. 1, 2015.

GINSBURG, F. Mediating culture: Indigenous media, ethnographic film and the production of identity. In: AEKEW, K.; WILK, R. (Ed.). The Antropology of media: a reader. Oxford: Blackwell, 2002.

HAKAK, Y. Haredi male bodies in the public sphere: negotiating with the religious text and secular Israeli men. Journal of Men, Masculinities and Spirituality, vol. 3, n. 2, 2009. . Spirituality and worldliness in Lithuanian Yeshivas. Jerusalém: Floersheimer Institute for Policy Studies, 2005. 
. Who shapes Haredi bodies: religious discourse or secular men? Journal of Men, Masculinities and Spiritualities, 3.2, 2009, p. 100-120.

KRONDOFER, B. Religion and gender: gender democracy in muilti-religious Europe. Transcrição de uma palestra dada no Heinrich Boell Foudantion, Berlin, 13 dez. 2007. PURSE, Lisa. Contemporary action cinema. Edinburgh: Edinburgh University Press, 2011. LONGHURST, R. Bodies: exploring fluid boundaries. London: Routledge, 2001

SLOTKIN, R. Gunfigther nation: the myth of the frontier in twentieth-century America. Nova Iorque: Maxwell Macmillan International, 1992.

TOPEL, M. A ortodoxia judaica e seus descontentes: dissidência religiosa no Israel contemporâneo. São Paulo: AnnaBlume, 2011.

TURNER, B. The body and society. Londres: Sage Publications, 1996. 